\title{
VERDADE, VERDADE HISTÓRICA E REGIMES DITATORIAIS: O DIREITO FUNDAMENTAL À VERDADE NOS PROCESSOS DE TRANSIÇÃO DE ESTADOS DE EXCEÇÃO PARA ESTADOS DEMOCRÁTICOS
}

\author{
TRUTH, HISTORICAL TRUTH AND DICTATORSHIPS: \\ THE FUNDAMENTAL RIGHT TO THE TRUTH IN TRANSITION PROCESS \\ OF UNDEMOCRATIC STATES TO DEMOCRATIC STATES
}

\author{
Gabrielle Tatith Pereira ${ }^{1}$
}

Recebido em: 07/09/2011

Aprovado em: 20/12/2011

\begin{abstract}
RESUMO
Este artigo tem como objetivo o estudo do direito à verdade como valor fundamental da democracia e como etapa necessária da justiça reparadora nos processos de transição de estados de exceção para estados democráticos. Pretende-se demonstrar que há uma relação necessária entre a democracia, enquanto espaço livre e politicamente autônomo de participação, e a construção da verdade. Nesse contexto, ressalta-se a importância das Comissões da Verdade como instrumentos de construção da verdade histórica nas sociedades pós-conflito, permitindo que todas as formas de autoritarismo, de violência e de opressão abandonem o estado de latência e sejam coletivamente trabalhadas, como um caminho necessário ao fortalecimento da democracia e ao pleno respeito aos direitos humanos.
\end{abstract}

Palavras-chave: Direito à verdade; Democracia; Justiça de transição.

\section{Introdução}

O presente trabalho destina-se ao estudo do direito à verdade enquanto valor fundamental da democracia $\mathrm{e}$ enquanto etapa indispensável da justiça reparadora nos processos de transição de estados de exceção para estados democráticos.

Partindo-se do pressuposto de que a verdade não tem sentido independentemente do homem e que é constru-

\begin{abstract}
This article has the purpose to study the right to truth as a fundamental value of democracy and as a necessary step of transitional justice in the transition process of an Undemocratic State to a Democratic State. Intended to demonstrate that that is a necessary relation between democracy, while a space free e politically autonomous of participation, and the construction of truth. In this context, stands out the importance of de Truth Commissions as an instrument of construction of historical truth in post-conflict societies, allowing that all forms of authoritarianism, of violence and of oppression abandon the abeyance and be collectively worked, as a way to strengthening democracy and to achieve full respect to human rights.
\end{abstract}

Keywords: Right to the truth; Democracy; Transitional justice.

ída pela ação conjunta dos indivíduos, pretende-se demonstrar que há uma relação necessária entre a democracia, enquanto espaço livre e politicamente autônomo de participação, e a construção da verdade. Pretende-se demonstrar, igualmente, que não há construção da verdade sem uma visão crítica do passado que permita, à coletividade, uma construção de sentido para os períodos de autoritarismo e de reiteradas violações aos direitos humanos, o que im-

' Bacharela em Direito pela Universidade Federal de Santa Maria/RS, Pós-Graduada em Direito Público Lato Sensu pela Universidade de AnhangueraUniderp/MS, Mestranda em Direito Constitucional, Constituição e Sociedade, pelo Instituto Brasiliense de Direito Público, Advogada do Senado Federal. 
plica dizer que a verdade histórica deve aflorar independentemente do decurso do tempo.

A justiça de transição representa um processo complexo e gradual, que necessariamente deve respeitar as peculiaridades e o tempo de cada sociedade. Nesse contexto, procura-se ressaltar a importância das Comissões da Verdade como instrumentos de construção da verdade histórica nas sociedades pósconflito, permitindo que todas as formas de autoritarismo, de violência e de opressão abandonem o estado de latência e sejam coletivamente trabalhadas, como um caminho necessário ao fortalecimento da democracia e ao pleno respeito aos direitos humanos.

No desenvolvimento do trabalho, são adotados os métodos de abordagem dialético e hipotético-dedutivo, bem como os métodos de procedimento histórico e comparativo.

$2 \mathrm{O}$ direito à verdade como fundamento do Estado Democrático de Direito

O conceito material e ontológico da palavra verdade perdeu-se no emaranhado do ser hermenêutico e do pragma lingüístico, sendo atualmente compreendido mais como um acerto provisório ou como um consenso dinâmico sobre as coisas do ou no mundo. A verdade como correspondência (constatação) foi substituída pela verdade como consenso intersubjetivo (construção) e, justamente por isso, se mostra indispensável para a formação das identidades individuais e coletivas numa sociedade.

A verdade não tem sentido em si mesma, independentemente do homem. A verdade adquire sentido quando construída para e pelo homem. A busca da verdade e a sua constante referência implícita e explícita nas relações sociais formam as comunicações humanas e a definição recíproca das identidades individuais e coletivas. Há uma interdependência entre a procura pela verdade e a socialização.
Entretanto, a formação das identidades individuais e coletivas deve se desenvolver num espaço livre e igualitário de construção da verdade, circunstância que somente é compatível com o Estado Democrático de Direito. A democracia pressupõe o respeito aos direitos políticos e à cidadania, os quais devem ser compreendidos na sua dimensão individual, como espaço de autonomia privada e correspondente às liberdades individuais, e também na sua dimensão coletiva, como espaço de autonomia pública e correspondente ao poder soberano emanado do povo, o qual se auto-organiza espontaneamente em sociedade e se submete ao domínio impessoal das leis. Essas dimensões da democracia (autonomia privada e autonomia pública) devem coexistir harmonicamente, porque não existe sociedade livre sem autonomia política, e não existe sociedade politicamente autônoma que não seja livre para participar ativamente do processo político decisório.

O conceito pós-moderno de democracia ultrapassa o critério majoritário para se consubstanciar na garantia de efetiva participação dos cidadãos no processo político, cuja legitimidade advém justamente da consciência e do sentimento de que exercem duplamente os papéis de destinatários e de coautores na tomada de decisões. A ação comunicativa de Habermas, instrumentalizada pelo discurso e pela linguagem, permite que os cidadãos construam conjunta $\mathrm{e}$ vivencialmente a ordem jurídica.

Nesse contexto, o livre acesso à informação e a livre troca de informações são indispensáveis para a construção da verdade (ou de suas várias versões), e não se pode conceber uma participação efetiva dos cidadãos no processo político decisório quando esse fluxo de informações é filtrado, reduzido ou manipulado pelo poder. A democracia pressupõe que os cidadãos estejam minimamente informados e que eles sejam capazes de formar convicções, de desenvolver o senso críticos sobre fatos 
presentes e passados, de expor idéias e de debatê-las no ambiente em que estão inseridos, sob pena de não serem capazes de influir no processo decisório.

Num estado em que a informação é ocultada ou deficiente, não há espaço seguro para o desenvolvimento da democracia. Norberto Bobbio (2002) reforça essa ideia ao afirmar que a democracia é o governo do poder visível ou, em outras palavras, é o governo do poder público em público. Para ele, o jogo de palavras é apenas aparente, já que a palavra "público" tem duplo significado, conforme contraposta a "privado", como na clássica distinção entre o ius publicum e o ius privatum dos juristas romanos, ou conforme contraposta a "secreto", enquanto não pertencente à coisa pública ou ao Estado, e correspondendo, portanto, ao que é visível.

Ao discorrer sobre a publicidade no poder autocrático, Norberto Bobbio (2002) refere que o segredo de Estado é a regra, não a exceção, de modo que as decisões políticas devem ser tomadas ao abrigo de qualquer tipo de público. $\mathrm{O}$ mais alto grau do poder público, aquele que toma as decisões vinculatórias para todos os súditos, confunde-se com a máxima concentração de poder na esfera privada do príncipe. Os atos da vida privada do soberano tornam-se públicos (núpcias, nascimento, morte, etc.), numa visibilidade luminosa (quase cegante), necessária para incutir, nos súditos, um sentimento de respeito e de temor reverencial, enquanto os atos de governo permanecem opacos, ocultando-se toda a ação desenvolvida para lhe assegurar a incontrolabilidade e a arbitrariedade.

Portanto, não há democracia sem visibilidade, e, quanto maior for o acesso dos cidadãos aos atos do governo, maior será a sua participação no processo decisório. $\mathrm{O}$ direito à verdade (ou à construção da verdade) é, pois, inerente ao regime democrático. No caso brasileiro, a Constituição da República de 1988 assentou o direito à verdade como um valor fundamental da democracia, deixando-o registrado em inúmeros artigos. É certo que esse direito fundamental não constou expressamente no rol do art. $1^{\circ}$, mas se faz presente na conceituação de quase todos os valores fundamentais ali destacados: a soberania (inc. I e parágrafo único), a cidadania (inc. II), a dignidade da pessoa humana (inc. III) e o pluralismo político (inc. IV).

Igualmente, a liberdade de informação genericamente considerada consta do rol de direitos e garantias fundamentais do art. $5^{\circ}$, nos incs. XIV, XXXIII, XXXIV, LXXII, IX, IV. A liberdade de informação como gênero compreende o direito de informar (liberdade de expressão) e o direito de ser informado. Este, em especial, deve ser compreendido em sua dimensão coletiva. O direito de ser informado não é um direito pessoal, nem um direito profissional, mas um direito essencialmente coletivo e indissociável do regime político. Representa um direito coletivo da informação ou um direito da coletividade à informação, oponível ao Estado.

A liberdade de informação é também protegida no art. 220, caput e parágrafos, da Constituição da República, no capítulo que trata da comunicação social. Há, inclusive, expressa vedação a qualquer tipo de censura de natureza política, ideológica ou artística. Com os modernos meios de comunicação em massa, o direito de informar, corolário do direito de manifestação do pensamento, e, portanto, originariamente de conotação individual, assume uma dimensão coletiva, enquanto direito de comunicação.

Ao tratar dos princípios que regem a atuação da Administração Pública (art. 37, caput), o constituinte originário expressamente elencou $\mathrm{o}$ princípio da publicidade, cuja atribuição de sentido não pode se dissociar do direito fundamental à informação, antes mencionado. O dever estatal de publicidade é uma contrapartida ao direito de 
ser informado e se destina a assegurar maior visibilidade ao poder. A difusão da informação, enquanto mecanismo de transparência, produz o efeito democratizante de aproximar os cidadãos do poder e, consequentemente, permitir que eles possam participar livremente do processo político decisório.

Há, portanto, uma relação direta entre o dever de publicidade da atividade estatal e o correlato direito à informação dos cidadãos. Quanto mais profunda for essa relação, mais esclarecidos, mais conscientes e mais livres serão os cidadãos para influir na construção do sistema normativo. Nesse sentido, é indissociável a relação entre o direito à verdade, o regime democrático e o exercício das liberdades. Isso significa, por outro lado, que o estado que sonega ou que manipula informações presentes ou passadas, violando o direito fundamental à verdade, impede a a-tuação livre e responsável dos cidadãos no processo decisório e, em decorrência, impede a efetivação de um estágio mais avançado da democracia.

A tensão que se estabelece entre o regime democrático e o direito à verdade, de um lado, e o passado e os regimes ditatoriais, de outro, será analisada no tópico seguinte.

\section{O direito à verdade, a história e os regimes ditatoriais}

A construção da verdade, num regime democrático, não pode prescindir da verdade histórica, do confronto das múltiplas fontes de informação disponíveis. A democracia que se alicerça na incerteza sobre os compromissos e sobre os projetos que lhe servem de fundamento é frágil, imatura, insegura e estará sempre à espera da revelação de seus enganos $\mathrm{e}$ da fragilidade de seus laços. A conciliação nacional não se torna definitiva quando os conflitos não são resolvidos.

O regime democrático é incompatível com a mentira, com a obscuridade. A sua consolidação depende da discussão aberta, livre e sem preconceitos dos fatos passados e presentes, dos erros e acertos, num confronto saudável e necessário entre as mais diferentes versões disponíveis à coletividade. Essa constatação assume maior importância quando o passado é marcado por períodos de restrição ou de supressão de direitos humanos. A transição de um estado de exceção para um estado democrático revela-se um processo complexo de maturação do poder, das instituições públicas e privadas e da própria sociedade. É inerente a esse processo que todas as formas de autoritarismo, de violência e de opressão abandonem o estado de latência e sejam coletivamente trabalhadas, como um caminho necessário ao fortalecimento da democracia e ao pleno respeito aos direitos humanos.

A construção da verdade no período da ditadura militar instaurada em 1964 é indispensável para uma adequada construção de sentido do regime ditatorial e, mais significativamente, para uma adequada construção de sentido do regime democrático instaurado com a ordem constitucional de 1988. As práticas autoritárias do Estado, notadamente das instituições militares e policiais, o sentimento de impunidade, a quebra da confiança dos cidadãos na ordem jurídica, entre outros, são fatores que se perpetuam no Estado Democrático Brasileiro como conseqüência do desenvolvimento incompleto e retardado da justiça de transição.

O regime democrático não se instaura tão somente pela promulgação de uma nova ordem jurídica, ainda que tal seja indispensável. O processo de transição é gradual, e o poder estatal que se pretenda legítimo e verdadeiramente democrático deve ser um agente propulsor da construção da verdade, passada e presente, e não um agente opressor e repetidor das práticas antidemocráticas.

Nesse contexto é que se inserem as comissões da verdade, da verdade e da memória ou da verdade e da reconciliação. Constituem uma alterna- 
tiva não-judicial, mas imparcial, para a investigação das distintas versões e dos documentos, notadamente estatais, relacionados ao período ditatorial. $\mathrm{O}$ trabalho isento e responsável dessas comissões da verdade minimiza os traumas e reduz os fatores de desagregação nas sociedades pós-conflito, contribuindo para o maior esclarecimento e para a maior conscientização da coletividade acerca da importância do exercício pleno das liberdades públicas.

O objetivo central das comissões é a construção da verdade, acompanhada da construção de sentido para a experiência ditatorial e para a consolidação da experiência democrática. Portanto, trazem em si um valor histórico inestimável, porquanto revelam uma parte da história do país que antes era ocultada e não integrava o discurso oficial. Entretanto, as comissões da verdade possuem uma significação tão ampla, que os seus resultados ultrapassam as questões concernentes ao conhecimento e ao tratamento da informação para igualmente alcançarem uma importância jurídica, política, documental e simbólica.

Sob o prisma jurídico, destacam-se os processos judiciais que poderão advir para a responsabilização de perpetradores (responsabilidade individual), bem como para a reparação das vítimas e seus familiares (responsabilidade do Estado). Sob o prisma arquivístico, os documentos identificados e catalogados pelas comissões da verdade tornam-se acessíveis ao público em geral e aos estudiosos, integrando o patrimônio histórico e cultural do país. Sob o prisma político, a revelação oficial das faces ocultas do regime ditatorial, notadamente das práticas reiteradas de violações dos direitos humanos por agentes do estado, desperta a consciência dos cidadãos para a importância da democracia e para a necessidade de participarem, cada vez mais, do processo político decisório. Surge também um sentimento coletivo de repúdio aos agentes públicos responsáveis pelos atos de exceção, o que contribui para que sejam excluídos do cenário político nacional ou, no mínimo, para que percam legitimidade no exercício de funções públicas. Por fim, sob o prisma simbólico, tem-se uma resposta adequada da sociedade a toda a forma de ditadura e a toda a forma de violação dos direitos humanos.

Os múltiplos valores que estão agregados ao trabalho das comissões da verdade as tornam etapa indispensável a uma justiça reparadora que pretenda suplantar os resquícios de um período ditatorial e conduzir a sociedade a um regime verdadeiramente democrático. Desse modo, enquanto a construção da verdade for obstada pelo Estado, que se perpetua invisível e autoritário, a justiça transicional não estará completa e não haverá espaço para o desenvolvimento de uma sociedade livre e politicamente autônoma. Independentemente do decurso do tempo, uma vez que o direito à verdade é um direito atemporal, será sempre o momento de aperfeiçoar a democracia.

\section{$4 \mathrm{O}$ direito à verdade como um direi- to atemporal}

O direito fundamental à verdade (ou à construção da verdade) é um valor absoluto, irrenunciável e não se sujeita à caducidade com o decurso do tempo. Essa compreensão é essencial para a justiça de transição, porque um passado de regime ditatorial e de sistemáticas violações a direitos humanos não pode ser sepultado e esquecido pelo Estado e pela sociedade. A superação de períodos autoritários não se apresenta imediata, mesmo quando os ditadores são retirados do poder em processos de ruptura. Ao contrário, a introdução de um regime democrático revela-se um processo gradual, complexo, multifatorial e frequentemente permeado de retrocessos. É um processo no qual são necessárias reformas políticas, jurídicas e institucionais significativas, para as quais a justiça reparadora é um caminho necessário. 
Ademais, a situação particular de cada país cria condições mais ou menos favoráveis à justiça transicional. É significativo, por exemplo, o modo como se dá a queda do poder autoritário, se exclusivamente por forças internas (processo endógeno) ou se com o auxílio de forças externas (processo exógeno), se de forma violenta ou negociada. Quanto mais negociada a redemocratização, mais força política dispõe o poder arbitrário para impor condições como a ocultação de documentos públicos, a anistia de agentes públicos executores e colaboradores, a manutenção de cargos e de funções públicas relevantes, etc., os quais se constituem em entraves à justiça de transição.

Não há, portanto, um tempo exato para a justiça transicional. Há casos em que ela se instaura imediatamente após o término do regime ditatorial e conclui seus trabalhos em curto prazo. Há casos em que ela inicia os trabalhos logo após a redemocratização, mas as atividades se prolongam por muitos anos. E há igualmente casos em que as etapas de transição se protraem no tempo e começam a ser implementadas muitos anos depois de encerrado o período de exceção.

Tampouco se pode estabelecer uma relação diretamente proporcional entre o prazo de duração de um regime autoritário e o prazo para uma adequada justiça transicional, porque são muitas as variáveis de um país para o outro. Entretanto, havendo uma semelhança considerável entre outros fatores, segundo Jon Elster, há uma tendência a que, quanto menor a duração do regime autocrático, mais vivas estejam as memórias dos abusos, mais urgente seja o apelo emocional por retribuição e mais imediato seja o início da justiça reparadora. Nas ditaduras de longa duração, a intensidade das emoções e a exigência de retribuição dependerão do período em que as maiores atrocidades foram perpetradas.

Ressalte-se, contudo, que, muito embora o anseio social por justiça seja um importante instrumento de pressão política, não é o único, tampouco o determinante. As etapas da justiça transicional são indispensáveis para curar as feridas coletivas, para expurgar resquícios autoritários e para criar um ambiente propício ao pleno gozo das liberdades públicas, haja ou não um forte apelo da sociedade nesse sentido.

A democracia pressupõe um espaço de construção, no qual os cidadãos se reconhecem como iguais e como igualmente aptos a participar do processo político decisório. $\mathrm{Na}$ transição democrática, há uma clara mudança de perspectiva dos indivíduos enquanto membros de uma coletividade, os quais deixam de ser meramente súditos para se transformarem em cidadãos e, como tais, criadores e destinatários da nova ordem jurídica.

Esse processo é deveras complexo e dificilmente se operaria numa sociedade pós-conflito, sem os mecanismos da justiça de transição. Significa dizer, então, que ela é um pressuposto necessário para a consolidação do estado democrático de direito, e que não há tempo certo para o seu início ou o seu prosseguimento. Além do mais, a justiça transicional compreende um conjunto integrado de ações (verdade, reparação às vítimas, persecução de perpetradores, reforma das instituições e reconciliação), e o Estado deve se esforçar para implementá-las no máximo grau possível. Não é lícito ao Estado optar por algumas ações em detrimento de outras. Ainda que sejam ações independentes, não são alternativas, e o Estado deve cumpri-las com boa-fé.

Nesse sentido, o decurso do tempo não se contrapõe à justiça transicional como um óbice intransponível. Ao contrário, a justiça de transição deve respeitar o tempo que cada sociedade necessita para cumprir com as suas etapas e para caminhar solidamente rumo à democracia. Incumbe a cada país a tarefa de decidir quando e como as ações da justiça de transição serão concretizadas. 
E, se essa premissa é verdadeira em relação ao todo (justiça transicional), o é em relação a cada uma das suas partes, respeitadas as particularidades de cada ordenamento jurídico. Dessa forma, o direito à verdade permanece incólume ao decurso do tempo, a despeito da resistência de alguns Estados redemocratizados em disponibilizar ao público os arquivos do período ditatorial. A ocultação de documentos públicos tem enorme significação, porque evidencia a continuidade das práticas autoritárias e da invisibilidade do poder passado e presente. Além do mais, impede que o poder público assuma integralmente a responsabilidade pelos abusos praticados por seus agentes e evidencia o baixo grau de comprometimento do Estado com o regime democrático instaurado.

Aliás, a recalcitrância do Estado em disponibilizar, à sociedade, os arquivos públicos do período ditatorial confirma a (ainda presente) suscetibilidade do regime democrático a atos autoritários, reforçando a necessidade da justiça de transição e, mais especificamente, da busca da construção coletiva da verdade e da construção de sentido a um passado de graves e repetidas violações aos direitos humanos.

Enquanto o direito à informação for deficiente e manipulado pelo poder público, não haverá espaço livre e politicamente autônomo para a formação das identidades individuais e coletivas e, consequentemente, para o pleno exercício das liberdades públicas.

Por outro lado, não se pode olvidar que a democracia é um processo dinâmico e de constante aperfeiçoamento. Nesse sentido, e respeitadas as particularidades de cada sociedade, o presente é sempre o tempo de revisitar o passado (por mais cruel que ele se revele) e de aprender com os erros e com os acertos, construindo novos paradigmas e novos valores, mais éticos e mais pluralistas para a sociedade. O esquecimento, muitas vezes imposto ou fomentado pelo Estado, é o caminho mais ineficaz para a consolidação do regime democrático, porque suprime as responsabilidades individuais e coletivas e porque perpetua o estado de inércia coletiva decorrente da opressão e do medo, circunstâncias incompatíveis com o papel ativo e responsável que se espera dos cidadãos na ordem democrática.

Sob esse prisma, e conforme se verá a seguir, também para o Estado brasileiro é tempo de construir a verdade a respeito da ditadura militar instaurada em 1964.

\section{0 direito à verdade e a ditadura militar brasileira de 1964 a 1985}

A restauração do regime democrático no Brasil foi resultado de infindáveis costuras políticas, equilibradas precariamente entre os defensores do retorno à democracia e os militares resistentes. Diferente de uma ruptura política, as peculiaridades da realidade brasileira culminaram numa transição negociada, quase como uma continuação política, na qual os principais líderes permaneceram ocupando funções públicas relevantes e participando ativamente das decisões no novo regime. Essa constância dos fatores reais de poder, no dizer de Lassale, restringiu muito as potencialidades da justiça reparadora brasileira, apesar da nova ordem jurídica em construção.

A Lei de Anistia, promulgada em 1979, ainda sob a égide de um estado de exceção, é uma clara consequência do controle exercido pelas forças autoritárias durante o processo de abertura política. O mesmo se pode dizer dos documentos públicos produzidos durante o regime ditatorial, os quais poderiam desvendar a prática institucionalizada de prisões ilegais, de tortura, de assassinatos, de estupros, etc., e que, em parte, permaneceram (e permanecem) classificados como de "segurança nacional", inacessíveis ao público, e, noutra parte, foram considerados oficialmente como destruídos ou desaparecidos. 
A restrição ao princípio da publicidade em defesa da "segurança nacional" representou, no passado, a total inexistência de uma vontade política de atribuição de responsabilidades individuais e coletivas. Transcorridos anos da reintrodução da democracia, a perpetuação do poder invisível é cada vez mais dissonante dos valores fundamentais da sociedade democrática brasileira, a qual exige um compromisso sério e responsável dos seus legítimos representantes na condução do interesse público.

É certo que houve alguns avanços quanto ao direito à verdade, desde a Constituição da República de 1988. Entretanto, tais avanços resultaram do esforço de segmentos da sociedade civil e de alguns órgãos públicos, inexistindo, todavia, uma política estatal de abertura de arquivos públicos.

O primeiro passo significativo, em termos de verdade e memória, foi o livro Brasil: nunca mais, de 1985, originado da iniciativa de um pequeno grupo de defensores dos direitos humanos, com o auxílio da Arquidiocese de São Paulo e do Conselho Mundial de Igrejas, o qual foi elaborado completamente à revelia do Estado. Utilizando-se de fatos registrados em processos do Superior Tribunal Militar (STM), o livro permitiu a compreensão detalhada de como funcionava o aparato de repressão durante o período da ditadura militar.

A primeira manifestação oficial do Estado Brasileiro sobre o período de exceção democrática ocorreu com a obra Direito à memória e à verdade, que resultou do trabalho realizado pela Comissão Especial sobre Mortos e Desaparecidos Políticos, instituída pela Lei $n^{\circ} 9.140 / 1995$, cujo objetivo era reconhecer pessoas desaparecidas, localizar corpos e emitir pareceres sobre os pedidos indenizatórios. Em decorrência dessa lei, primeiro instrumento normativo a contemplar o reconhecimento e a responsabilização do Estado pelas violações de direitos humanos na ditadura, as conclusões da Comissão, sintetizadas na obra, atribuíram a integrantes das forças de segurança a prática de diversos crimes contra os opositores do regime, já presos e submissos ao império do Estado, incluindo tortura, assassinato, esquartejamento, decapitação e ocultação de cadáveres.

Mais recentemente, a Lei $n^{\circ}$ 10.559/2002 instituiu a Comissão de Anistia, cujo objetivo principal é examinar os requerimentos administrativos de reparação econômica das vítimas e seus familiares pelos abusos praticados por agentes do Estado durante o regime ditatorial. Muito embora tal comissão não se destine especificamente à construção da verdade e da memória nacional, os documentos por ela produzidos têm um valor inestimável nesse processo.

A partir de esforços empreendidos pelo Governo Federal, foram também encaminhados, ao Arquivo Nacional, documentos públicos do regime de exceção relativamente aos extintos Serviço Nacional de Informações (SNI), Conselho de Segurança Nacio-nal e Comissão Geral de Investigações, além de arquivos do Departamento de Polícia Federal, do Gabinete de Segurança Institucional e de outros órgãos públicos. Após organizados e digitalizados, encontram-se acessíveis ao público em geral. Alguns estados da federação disponibilizaram ao público arquivos do Departamento de Ordem Política e Social - DOPS, a exemplo do Paraná, Rio de Janeiro, São Paulo, Goiás, etc., havendo registro, em alguns estados, de restrição de acesso a processos pessoais ou a documentos classificados como sigilosos ou reservados.

Os avanços citados, embora importantes, não satisfazem por completo as exigências da justiça reparadora, para a qual é indispensável a constituição de uma Comissão da Verdade, pelo próprio Estado, ou com o seu integral respaldo, à qual sejam disponibilizados os documentos públicos do período ditatorial, notadamente os produzidos pelas Forças Armadas. O trabalho desenvolvido pelas Comissões da Verdade compreende 
todo um processo, que tem início com o acesso amplo à informação, passa pelo seu adequado tratamento (verificação, organização, seleção, etc.) e culmina com a apresentação à sociedade de uma obra que (re)constrói a verdade sobre o período autoritário, permitindo-lhe uma construção de sentido desse passado, consubstanciada no reconhecimento de todos os indivíduos como iguais e como igualmente merecedores do respeito aos direitos humanos e na reconciliação nacional.

Com vistas a atingir esse propósito, foi recentemente sancionada a Lei $\mathrm{n}^{\circ} 12.528 / 2011$ pela Presidenta da República, que cria a Comissão Nacional da Verdade, com os seguintes objetivos (art. $3^{\circ}$ ): esclarecer os fatos e as circunstâncias de graves violações de direitos humanos praticadas no período fixado no art. $8^{\circ}$ do ADCT (1946-1988); promover o esclarecimento circunstanciado dos casos de torturas, mortes, desaparecimentos forçados, ocultação de cadáveres, ocorridos no Brasil ou no exterior, bem como suas autorias; identificar e tornar públicos os locais, as estruturas, as instituições e as circunstâncias relacionadas à prática de violações de direitos humanos, suas ramificações nos aparelhos estatais e na sociedade; encaminhar aos órgãos públicos competentes toda a informação que possa auxiliar na localização e identificação dos corpos e restos mortais dos desparecidos políticos, nos termos do art. $1^{\circ}$ da Lei $\mathrm{n}^{\circ}$ 9.140/1995; colaborar com o poder público para a apuração de violações de direitos humanos; recomendar a adoção de medidas e de políticas públicas para prevenir e assegurar a não-repetição de violações de direitos humanos, bem como promover a efetiva reconciliação nacional e; promover a reconstrução da história dos casos de graves violações de direitos humanos e colaborar para que seja prestada assistência às vítimas.

É importante ressaltar que, para a execução desses objetivos, a Comissão Nacional da Verdade poderá requisitar informações, dados e documentos de ór- gãos e entidades do poder público, ainda que classificados como sigilosos, em qualquer grau, bem como determinar a realização de perícias e diligências para coleta ou recuperação de informações, documentos e dados. Há também a previsão de que os militares e os servidores públicos têm o dever de colaborar com os trabalhos da Comissão (art. $4^{\circ}$, inc. II e IV, c/c o $\S 1^{\circ}$ da Lei $\left.\mathrm{n}^{\circ} 12.528 / 2011\right)$.

A tramitação desse projeto de lei provocou significativo desgaste político entre setores do Governo Federal, mais especificamente entre o Ministério da Defesa e o Ministério da Justiça. Essa tensão é perceptível, inclusive, em algumas passagens do texto de lei aprovado, a exemplo da expressa menção ao caráter não jurisdicional ou persecutório da Comissão Nacional da Verdade (art. $4^{\circ}, \S 4^{\circ}$, da Lei $\left.\mathrm{n}^{\mathrm{o}} 12.528 / 2011\right)$, bem como à necessidade de observância da Lei da Anistia na (art. $6^{\circ}$ da Lei ${ }^{\circ}$ 12.528/2011).

A recente Lei $n^{\circ} 12.527 / 2011$, que regulamenta o direito constitucional à informação, também provocou cizânia política. O texto sancionado estabelece diretrizes expressas de observância da publicidade como preceito geral e do sigilo como exceção, bem como do fomento da cultura da transparência no âmbito da Administração Pública (art. $3^{\circ}$, incs. I e IV, da Lei $\mathrm{n}^{\mathrm{o}}$ 12.527/2011). Ademais, no capítulo que trata das restrições de acesso à informação, vedase o sigilo de informação necessária à tutela judicial ou administrativa de direitos fundamentais, com a ressalva de que as informações ou documentos que versem sobre condutas violadoras de direitos humanos praticadas por agentes públicos ou a mando de autoridades públicas não poderão ser objeto de restrição de acesso (art. 21, caput e parágrafo único, da Lei ${ }^{\circ}$ 12.527/2011).

Ao tratar da classificação da informação quanto ao grau de sigilo e os prazos, a lei define expressamente quais documentos podem ser classificados como imprescindíveis à segurança da 
sociedade e do Estado (art. 23 da Lei $\left.\mathrm{n}^{\mathrm{o}} 12.527 / 2011\right)$ e, portanto, sujeitos à atribuição de sigilo. As informações poderão ser classificadas como ultrassecretas, secretas ou reservadas, com prazos de restrição de acesso, a contar da sua produção, de 25,15 e 5 anos respectivamente (art. 24, caput e $\S 1^{\circ}$ ) e, como regra, sem possibilidade de prorrogação (art. 24, § $4^{\circ}$ ). Apenas em situações excepcionais, os documentos classificados como ultrassecretos poderão ter a restrição de acesso prorrogada por uma Comissão Mista de Reavaliação de Informações, sempre por prazo determinado e limitado a uma única renovação do prazo previsto no art. $24, \S$ $1^{\circ}$ (art. $35, \S 1^{\circ}$, inc. III, e $\S 2^{\circ}$, da Lei ${ }^{\circ}$ 12.527/2011).

A tramitação desse projeto no Congresso Nacional foi tumultuada, especialmente em face da previsão de uma única prorrogação do prazo de restrição de acesso dos documentos ultrassecretos. Alguns agentes políticos trabalharam para suprimir a alteração do texto do projeto de lei, restabelecendo a redação original enviada pela Presidência da República ao Congresso Nacional, que contemplava a possibilidade de renovação, ad eternum, da restrição de acesso dos documentos ultrassecretos. A renovação ilimitada do sigilo estava prevista na legislação que, até então, disciplinava o acesso aos documentos públicos.

As leis recém-aprovadas, que diretamente dispõem sobre o direito fundamental à verdade, representam significativo avanço da democracia brasileira, notadamente no que diz respeito ao estabelecimento de um poder visível, transparente e acessível à participação e ao controle dos cidadãos.

O regime democrático pressupõe um espaço de liberdade e de autonomia dos indivíduos, igualmente reconhecidos e capazes, que é incompatível com a tutela ou a proteção do conhecimento pelo Estado. Nesse sentido, não cabe ao poder público selecionar arbitrariamen- te a informação que a sociedade está pronta a receber, ocultando o conhecimento que não lhe parece conveniente ou oportuno revelar, independentemente da motivação. A publicidade é a regra e o sigilo a exceção.

Se a democracia tem sua base de sustentação no compromisso e na responsabilidade compartilhada entre o Estado e os cidadãos, estes não podem ser privados do acesso à informação, especialmente quando esta informação está relacionada a períodos de exceção, caracterizados pela sistemática violação aos direitos humanos. A construção da verdade é essencial, mesmo que represente um processo difícil e doloroso à coletividade. É justamente como fruto desse amadurecimento e dessa construção de sentido que emergirá uma nova condição humana, na qual os indivíduos se reconhecerão como igualmente dignos e merecedores do respeito aos direitos humanos.

\section{Considerações finais}

O processo de construção da verdade revela-se indispensável para a formação das identidades individuais e coletivas numa sociedade. É a partir da busca da verdade e de sua constante referência (implícita e explícita) nas relações sociais que se formam as comunicações humanas e, consequentemente, a definição recíproca das identidades individuais e coletivas. Entretanto, a formação de identidades deve se desenvolver num espaço livre e igualitário de construção da verdade, circunstância que somente é compatível com o Estado Democrático.

O conceito pós-moderno de democracia ultrapassa o critério majoritário para se consubstanciar na garantia de efetiva participação dos cidadãos no processo político, cuja legitimidade advém justamente da consciência e do sentimento de que exercem duplamente os papéis de destinatários e de coautores na tomada de decisão. A ação comuni- 
cativa de Habermas, instrumentalizada pelo discurso e pela linguagem, permite que os cidadãos construam, conjunta e vivencialmente, a ordem jurídica.

Nesse contexto, o livre acesso à informação e a livre troca de informações são indispensáveis para a construção da verdade (ou de suas várias versões), e não se pode conceber uma participação efetiva dos cidadãos no processo político decisório, quando esse fluxo de informações é filtrado, reduzido ou manipulado pelo poder. Não há democracia sem visibilidade. $\mathrm{O}$ direito à verdade (ou à construção da verdade) é, pois, inerente ao regime democrático.

Partindo dessa premissa, não se há falar em verdade sem um olhar crítico sobre o passado. A construção da verdade não pode prescindir da verdade histórica, do confronto das múltiplas fontes de informação disponíveis. A democracia que desconhece os compromissos e os projetos que a fundamentam é imatura e estará sempre suscetível à ruptura de seus laços. O regime democrático é incompatível com a obscuridade, e a sua consolidação depende da discussão aberta, livre e sem preconceitos dos fatos passados e presentes, dos erros e acertos, num confronto saudável e necessário entre as mais diferentes versões disponíveis à coletividade.

Ademais, o retorno ao passado assume maior importância quando marcado por períodos de restrição ou de supressão de direitos humanos. A transição de um estado de exceção para um estado democrático revela-se um processo complexo de maturação do poder, das instituições públicas e privadas e da própria sociedade. É inerente a esse processo que todas as formas de autoritarismo, de violência e de opressão sejam coletivamente trabalhadas, como um caminho necessário ao fortalecimento da democracia e ao pleno respeito aos direitos humanos.

Nesse processo, o tempo deve ser concebido como um facilitador, não como um óbice. O direito fundamental à verdade (ou à construção da verdade) é um valor absoluto, irrenunciável e que não se sujeita à caducidade. Essa compreensão é essencial para a justiça de transição, porque um passado de regime ditatorial e de sistemáticas violações a direitos humanos não pode ser sepultado e esquecido pelo Estado e pela sociedade. A superação de períodos autoritários não se apresenta imediata. Ao contrário, a introdução de um regime democrático revela-se um processo gradual, complexo, multifatorial e frequentemente permeado de retrocessos.

Nesse sentido, as etapas da justiça transicional são indispensáveis para curar as feridas coletivas, para expurgar resquícios autoritários e para criar um ambiente propício ao pleno gozo das liberdades públicas, independentemente do decurso do tempo e independentemente de haver ou não um forte apelo da sociedade para tanto.

A transição democrática pressupõe uma mudança de perspectiva dos indivíduos enquanto membros de uma coletividade, os quais deixam de ser meramente súditos para se transformarem em cidadãos e, como tais, criadores e destinatários da nova ordem jurídica. Esse processo é extremamente complexo e dificilmente se operaria numa sociedade pós-conflito, sem os mecanismos da justiça de transição. Portanto, cada Estado deve decidir como e quando implementar o conjunto de ações que envolvem a justiça reparadora, a exemplo da constituição de Comissões da Verdade, independentemente do transcurso do tempo.

Não se pode olvidar que a democracia é um processo dinâmico e de constante aperfeiçoamento. Sendo assim, e respeitadas as particularidades de cada sociedade, o presente é sempre o tempo de revisitar o passado e aprender com os erros e com os acertos, construindo novos paradigmas e novos valores, mais éticos e mais pluralistas para a sociedade. O esquecimento é o caminho mais ineficaz para a consolidação do regime democrático. 
Conforme a experiência brasileira, a restrição ao princípio da publicidade em defesa da "segurança nacional" representou, no passado, a total ausência de uma vontade política de atribuição de responsabilidades individuais e coletivas. Decorridos anos da redemocratização, a perpetuação do poder invisível é cada vez mais dissonante dos valores fundamentais da sociedade democrática brasileira.

Os avanços verificados quanto ao direito à verdade, desde a Constituição da República de 1988, resultaram do esforço de segmentos da sociedade civil e de alguns órgãos públicos, inexistindo, todavia, uma política estatal de abertura de arquivos públicos. Não obstante, o regime democrático pressupõe um espaço de liberdade e de autonomia dos cidadãos, igualmente reconhecidos $\mathrm{e}$ capazes, que é incompatível com a tutela ou com a proteção do conhecimento pelo Estado. A publicidade é a regra e o sigilo, a exceção.

Considerando-se que a democracia assenta-se no compromisso e na responsabilidade compartilhada entre o Estado e os cidadãos, estes não podem ser privados do acesso à informação, especialmente quando esta informação está relacionada a períodos de exceção, caracterizados pela sistemática violação aos direitos humanos. A construção da verdade é essencial mesmo que represente um processo difícil e doloroso à coletividade. É como fruto desse amadurecimento e dessa construção de sentido que emergirá uma nova condição humana, mais ética e pluralista, na qual os indivíduos se reconhecerão como igualmente dignos e merecedores do respeito aos direitos humanos.

\section{Referências bibliográficas}

ARENDT, Hannah. Origens do Totalitarismo. São Paulo : Companhia das Letras. Trad.: Roberto Raposo. 1989.

BARBOSA, Marco Antônio Rodrigues;
VANUCCHI, Paulo. Resgate da memória e da verdade: um direito de todos. Memória e Verdade - A Justiça de Transição no Estado Democrático Brasileiro. Belo Horizonte : Fórum. 2009. P. 55-67.

BARROS, Edgar Luiz de. Os governos militares. São Paulo : Contexto. 5 ed. 1997.

BOBBIO, Norberto. O futuro da democracia. São Paulo : Paz e Terra. $8^{\mathrm{a}}$ ed. 2002.

CATELA, Ludmila da Silva. Do segredo à verdade... processos sociais e políticos na abertura dos arquivos da repressão no Brasil e na Argentina. Desarquivando a Ditadura II - Memória e Justiça no Brasil. Organizadores: SANTOS, Cecília Macdowell; TELES, Edson; TELES, Janaína de Almeida. São Paulo : Ed. Hucitec. 2009. P. 445-471.

COSTA, Célia Maria Leite. O direito à informação nos arquivos brasileiros. Ditadura e Democracia na América Latina - Balanço histórico e perspectivas. Organizadores: FICO, Carlos; FERREIRA, Marieta de Moraes; ARAÚJO, Maria Paula; QUADRAT, Samantha Viz. Rio de Janeiro : Editora FGV. 2008. P. 17-26.

ELSTER, Jon. Closing Books - Transitional Justice in Historical Perspective. Cambridge : Cambrigde University Press. 2004.

FICO, Carlos. Versões e controvérsias sobre 1964 e a ditadura militar. Rev. Bras. Hist., São Paulo, v. 24, n. 47, 2004. Disponível em $\quad<$ http://www.scielo.br/scielo. php? script $=$ sci_arttext\&pid $=$ S0102$-01882004000100003 \& \operatorname{lng}=$ pt\&nrm= iso $>$. acessos em 21 jul. 2011. doi: 10.1590/S0102-01882004000100003.

FICO, Carlos. O golpe de 1964 e o pa- 
pel do governo dos Estados Unidos. Ditadura e Democracia na América Latina - Balanço histórico e perspectivas. Organizadores: FICO, Carlos; FERREIRA, Marieta de Moraes; ARAÚJO, Maria Paula; QUADRAT, Samantha Viz. Rio de Janeiro : Editora FGV. 2008. P. 53-76.

GEREMBERG, Alice Leal Wolf. O Procedimento Discursivo-Argumentativo no Interior do Espaço Público: Aproximações do Modelo Alexiano à Democracia Deliberativa Habermasiana. Perspectivas atuais da Filosofia do Direito. Organizadores: MAIA, Antonio Cavalcanti; MELO, Carolina de Campos; CITTADINO, Gisele; POGREBINSCH, Thamy. Rio de Janeiro : Lumen Juris. 2005. P. 63-89.

HAYNER, Priscilla. Enfrentando crímenes pasados y la relevancia de las comisiones de la verdad. Verdad, memoria y reconstrucción - Estudios de caso y analisis comparado. Serie Justicia Transitional. Editor Mauricio Romero. 2008. P. 45-75.

KISHI, Sandra Akemi Shimada. Direito à informação e à participação na Justiça de Transição. Memória e Verdade - A Justiça de Transição no Estado Democrático Brasileiro. Belo Horizonte : Fórum. 2009. P. 273-291.

MEZAROBBA, Glenda. O que é Justiça de Transição? Uma análise do conceito a partir do caso brasileiro. Memória e Verdade - A Justiça de Transição no Estado Democrático Brasileiro. Belo Horizonte : Fórum. 2009. P. 37-53.

OST, François. O tempo do direito. Tradução: Élcio Fernandes. Bauru : Edusc. 1999. PA, Alfredo Boccia. Los "archivos del horror" del Paraguay: los papeles que resignificaron la memória del stronismo. Ditadura e Democracia na América Latina -
Balanço histórico e perspectivas. Organizadores: FICO, Carlos; FERREIRA, Marieta de Moraes; ARAÚJO, Maria Paula; QUADRAT, Samantha Viz. Rio de Janeiro : Editora FGV. 2008. P. 27-49.

RAPOSO, Marcello Neves M.. Poder, Direito e Verdade: o Direito como "Máscara" do funcionamento Efetivo das Microrrelações Produtivas do Poder/Saber. Perspectivas atuais da Filosofia do Direito. Organizadores: MAIA, Antonio Cavalcanti; MELO, Carolina de Campos; CITTADINO, Gisele; POGREBINSCH, Thamy. Rio de Janeiro : Lumen Juris. 2005. P. 189212.

REALE, Miguel. Da Revolução à Democracia. São Paulo : Convívio. $2^{\mathrm{a}}$ Ed. 1977.

SAMPAIO, José Adércio Leite; ALMEIDA, Alex Luciano Valadares de. Verdade e história: por um direito fundamental à verdade. Memória e Verdade - A Justiça de Transição no Estado Democrático Brasileiro. Belo Horizonte : Fórum. 2009. P. 249. 272.

SILVA, José Afonso da. Comentário Contextual à Constituição. São Paulo : Malheiros. $3^{\text {a }}$ Ed. 2007.

TAVARES, André Ramos; AGRA, Walber de Moura. Justiça Reparadora no Brasil. Memória e Verdade - A Justiça de Transição no Estado Democrático Brasileiro. Belo Horizonte : Fórum. 2009. P. 69-91.

WEICHERT, Marlon Alberto. Arquivos secretos e direito à verdade. Desarquivando a Ditadura II - Memória e Justiça no Brasil. Organizadores: SANTOS, Cecília Macdowell; TELES, Edson; TELES, Janaína de Almeida. São Paulo : Ed. Hucitec. 2009. P. 406-423. 
ZYL, Paul Van. Promoviendo la justicia transicional em sociedades pós-conflicto. Verdad, memoria y reconstrucción - Estudios de caso y analisis comparado. Serie Justicia Transitional. Editor Mauricio Romero.

P. 14-44. 2008.

SOCIAIS E HUMANAS, SANTA MARIA, v. 25, n. 01, janeiro/junho 2012, p. 9-22 